\title{
Enhanced metallurgical coke quality through incorporation of the pitch during biomass/coal co-carbonization
}

\author{
Linbo Qin ${ }^{1 \mathrm{a}}$, Jun $\mathrm{Han}^{1 \mathrm{~b} *}$, Ke Fang ${ }^{1}$, Xiufeng Chen ${ }^{1}$ and Gaoming $\mathrm{Wu}^{2}$ \\ ${ }^{1}$ College of Resources and Environment Engineering, Wuhan University of Science and \\ Technology, Wuhan, 430081, P.R. China \\ ${ }^{2}$ Design \& Research Institute of Wuhan Iron \& Steel Group, Wuhan, 430080, P.R. China \\ aemail: qinlinbo@wust.edu.cn; ${ }^{b}$ email: hanjun@wust.edu.cn
}

\begin{abstract}
Keywords: Biomass; Pitch; Co-carbonization; Coke
Abstract. Experimental comparisons of coke qualities with and without pitch incorporation during biomass/coal co-carbonization were conducted. Meanwhile, effects of biomass and pitch on the thermoplastic properties of the biomass/coal blends and coke quality indexes, such as M10, M40, CRI, and CSR were also discussed. Results indicated that the thermoplastic properties of the biomass/coal blends were enhanced by incorporation of the pitch. Adding $1.0 \%$ pitch could obviously enhance the coke quality indexes, the maximum amount of PSD and ST addition can be increased to $9.0 \%$ and $6.0 \%$, respectively. Meanwhile, it was also found that the addition of PSD has no significant influence on the coke quality indexes when the mass concentration of PSD is below 6\%, whereas the coke quality indexes are degraded gradually as the mass concentration of PSD is above $6 \%$. The addition of $\mathrm{ST}$ also has a negative influence on the coke quality indexes. Even the addition of $3 \%$ ST will reduce the maximum fluidity of blend coals.
\end{abstract}

\section{Introduction}

Metallurgical coke is an essential industrial material in iron and steel industry, which acts as a fuel, a reducing agent, and a permeable support of blast-furnace charge during the iron-making process. It is forecasted that the consumption of coke in 2020 will be kept at 370 million tons, which needs 500 million tonnes of coking coal [1]. However, only part of coal can be used for making coke. It was reported that the reserve of coking coal was only $27 \%$ of the total coal reserve in China, about 276 billion tons [2]. Hence, the reduced availability and high cost of prime coking coals has caused great interest in the use of additives in coking blends. The main purpose of the additive is to preserve the coking properties of the blend by either replacing the prime coking coal or modifying the properties of poor coking coals to produce blends that behave the same as prime coking coals. The use of biomass as additive in coking blends offers the advantages of reducing production costs by replacing expensive prime coking coals and also reducing non-renewable carbon emissions into the atmosphere as biomass is carbon neutral[3].

Some studies have found that the fluidity of the coking blend and the coke strength are usually reduced by the addition of biomass [4-5]. Castro Diáz et al. found sugar beet could be added to metallurgical coals up to $5 \mathrm{wt} \%$ without altering the viscoelastic properties of the coals, whereas pine wood and miscanthus reduced the fluidity even with $2 \mathrm{wt} \%$ addition [5]. MacPhee et al. pointed out that the addition of $5 \mathrm{wt} \%$ biomass to coking coals reduced the coke strength after reaction (CSR) index from 56.7 to 35.8 [3]. Our previous studies also proved that the addition of $5 \mathrm{wt} \%$ biomass to coking coals reduced the coke strength after reaction (CSR) index [6]. It was reported that increasing the heating rate of carbonization can improve fluidity development and coke strength [7]. However, these fast heating rates are not feasible for commercial application. Some studies also proposed that compressive forming at $200{ }^{\circ} \mathrm{C}$ could effectively decrease the contact area by increasing both particle size and density, which will inhibited the reduction of coke quality [8]. Indeed, biomass is a physically 
inert component in the blend with chemical activity, the addition of biomass particles increases the amount of inert particles in the plastic stage; which resulted in the concentration of active components in the plastic stage will be reduced [6]. Thus, adding active components such as pitch in biomass/coal blends can improve the coke quality due to increasing the concentration of active components. But little studies about the effect of pitch on the coke quality during coal/biomass co-coking have been reported.

In this paper, experimental comparisons of coke qualities with and without pitch incorporation during biomass/coal co-carbonization were conducted. Meanwhile, effects of biomass and pitch on the thermoplastic properties of the biomass/coal blends and coke quality indexes, such as M10, M40, CRI, and CSR were also investigated.

\section{Materials and methods}

\section{Materials}

A blended coal, one type of pitch (PT), and two types of biomass such as pine sawdust (PSD), and straw (ST) were used in this study. Before the experiments, the blended coal was milled to less than 3 $\mathrm{mm}$, while the biomasses were milled to $0.3 \sim 0.6 \mathrm{~mm}$. Then milled biomass was mixed with the milled coal at a mass percentage of $3 \%, 6 \%, 9 \%$ and $12 \%$, respectively. Lastly, pitch was also incorporated into the biomass/coal blends with the mass fraction of $1.0 \%$. The basic characteristics of the blend coal, biomass and pitch were listed in Table 1 . The ultimate analysis was performed by an elemental analyzer (CHN EL-Ш, Vario). The proximate analysis was carried out using a muffle furnace according to GB/T212-2008 standard procedure. The caking index (G) was used to characterize the caking property of coal. The measurement was carried out according to the National Standard of China (GB5447-85). The thermoplastic properties of the biomass/coal blends were estimated in a constant-torque Gieseler plastometer (PL-2006A, China), according to the GB/T 25213-2010 standard procedure.

Table 1 The basic characteristics of the blend coal, biomass and pitch

\begin{tabular}{|c|c|c|c|c|c|c|c|c|c|}
\hline \multirow{2}{*}{$\begin{array}{l}\text { Sampl } \\
\text { es }\end{array}$} & \multicolumn{4}{|c|}{ Proximate analysis \%(ad) } & \multicolumn{4}{|c|}{ Ultimate analysis\% (ad) } & \multirow{2}{*}{$\begin{array}{c}\text { Bulk } \\
\text { density }\left(\mathrm{kg} / \mathrm{m}^{3}\right)\end{array}$} \\
\hline & Moisture & Ash & Volatile & $\begin{array}{l}\text { Fixed } \\
\text { carbon }\end{array}$ & Carbon & Hydrogen & Nitrogen & Sulfur & \\
\hline Coal & 1.99 & 9.43 & 25.96 & 62.62 & 72.24 & 4.8 & 1.12 & 1.07 & 837 \\
\hline PSD & 11.04 & 2.91 & 60.69 & 25.36 & 44.46 & 4.89 & 0.23 & 0.13 & 325 \\
\hline ST & 6.76 & 8.33 & 70.85 & 14.06 & 39.78 & 5.42 & 0.7 & 0.28 & 236 \\
\hline PT & 4.21 & 0.39 & 4.27 & 91.13 & 93.14 & 4.59 & 0.74 & 0.83 & 1250 \\
\hline
\end{tabular}

\section{Methods}

In order to study the effect of PSD on coke quality parameters(such as CSR, CRI, M40, M10 of the cokes), the coal/PSD blends were carbonized in a $5 \mathrm{~kg}$ laboratory-scale coke oven. The experimental process was described in our previous paper [6]. The cold mechanical strength (M40 and M10) of the cokes was assessed according to Chinese standard (GB/T 2006-2008), and the hot performances (CRI and CSR) of coke was also measured according to GB/T2006-94.

\section{Results and Discussions}

Effect of biomass and pitch addition on the thermoplastic properties

The quality of produced coke greatly depends on the thermoplastic properties of the biomass/coal blends [3]. So the influence of the biomass or pitch addition on thermoplastic properties of coal blends was probed by Gieseler test. Table 2 shows the thermoplastic parameters of the raw coal and its blends with $3 \sim 12 \mathrm{wt} \%$ biomass or pitch additions. The plastic range of raw coal was $88^{\circ} \mathrm{C}$. Compared with raw coal, the softening temperature of PSD/coal blends increased slightly, while the resolidification 
temperature of PSD/coal blends decreased significantly. These leads to the reduction of plastic range as high as $18{ }^{\circ} \mathrm{C}$ when the PSD addition is $12 \%$. Meanwhile, the addition of ST also decreased the resolidification temperature and reduced the plastic range of the ST/coal blends when the addition of ST is increased from $3 \%$ to $12 \%$. The more significant reduction of the plastic range of the blends with $12 \%$ PSD or ST addition should be attributed to the higher oxygen content and lower melting temperature in PSD or ST at higher temperature [8]. Table 2 also indicates that $1.0 \%$ pitch addition could obviously suppress the reduction of plastic range. For example, the plastic ranges with the PSD addition of $3.0 \%, 6.0 \%, 9.0 \%$ and $12.0 \%$ are respectively increased from $85^{\circ} \mathrm{C}, 80^{\circ} \mathrm{C}, 76^{\circ} \mathrm{C}, 70{ }^{\circ} \mathrm{C}$ to $92^{\circ} \mathrm{C}, 89^{\circ} \mathrm{C}, 86^{\circ} \mathrm{C}, 82^{\circ} \mathrm{C}$ when $1.0 \%$ pitch is added. As for the ST addition, the plastic ranges with the $3.0 \%, 6.0 \%, 9.0 \%$ and $12.0 \% \mathrm{ST}$ addition are increased from $82^{\circ} \mathrm{C}, 77^{\circ} \mathrm{C}, 75^{\circ} \mathrm{C}, 72{ }^{\circ} \mathrm{C}$ to $88^{\circ} \mathrm{C}, 81^{\circ} \mathrm{C}$, $80^{\circ} \mathrm{C}, 76^{\circ} \mathrm{C}$, respectively, when $1.0 \%$ pitch is added. The above phenomenal can be attributed to the higher melting temperature of the pitch at higher temperature. Additionally, it has been proved by the MOF model that the $\log (\mathrm{MF})$ value ranged from 2 to 3 was the optimum window to obtain a strong coke [5]. The log (MF) value of the biomass/coal blends is reduced with the PSD or ST addition, while it is increased with $1.0 \%$ pitch addition. Thus, the thermoplastic properties of the coal were deteriorated by incorporation of the PSD or ST, while it was enhanced by incorporation of the pitch. So it is expected that the biomass/coal blends with pitch addition can produce coke with good strength.

Table 2 The results of thermoplastic parameters

\begin{tabular}{ccccccc}
\hline Sample & $\mathrm{G}$ & $\mathrm{T}_{\mathrm{s}}{ }^{0} \mathrm{C}$ & $\mathrm{T}_{\mathrm{f}}{ }^{0} \mathrm{C}$ & $\mathrm{T}_{\mathrm{r}}{ }^{0} \mathrm{C}$ & $\mathrm{P}_{\mathrm{r}} \rho^{0} \mathrm{C}$ & $\log (\mathrm{MF}) / \mathrm{ddpm}$ \\
\hline $\mathrm{RC}$ & 82 & 407 & 445 & 495 & 88 & 2.7 \\
\hline RC+3\% PSD & 82 & 408 & 446 & 493 & 85 & 2.8 \\
RC+6\% PSD & 79 & 411 & 454 & 491 & 80 & 2.9 \\
RC+9\% PSD & 77 & 414 & 455 & 490 & 76 & 3.2 \\
RC+12\% PSD & 74 & 418 & 457 & 488 & 70 & 3.5 \\
\hline RC+3\% PSD+1\%PT & 83 & 404 & 444 & 496 & 92 & 2.5 \\
RC+6\% PSD+1\%PT & 82 & 406 & 447 & 495 & 89 & 2.7 \\
RC+9\% PSD+1\%PT & 81 & 408 & 450 & 494 & 86 & 2.8 \\
RC+12\% PSD+1\%PT & 77 & 409 & 451 & 491 & 82 & 3.0 \\
\hline RC+3\% ST & 81 & 411 & 454 & 493 & 82 & 2.8 \\
RC+6\% ST & 79 & 413 & 456 & 490 & 77 & 3.2 \\
RC+9\% ST & 77 & 414 & 456 & 489 & 75 & 3.5 \\
RC+12\% ST & 73 & 416 & 459 & 488 & 72 & 3.8 \\
\hline RC+3\% ST+1\%PT & 82 & 408 & 451 & 496 & 88 & 2.6 \\
RC+6\% ST+1\%PT & 80 & 411 & 454 & 492 & 81 & 2.8 \\
RC+9\% ST+1\%PT & 79 & 413 & 456 & 493 & 80 & 2.9 \\
RC+12\% ST+1\%PT & 76 & 415 & 458 & 491 & 76 & 3.1 \\
\hline
\end{tabular}

$\mathrm{T}_{\mathrm{s}}$ : softening temperature; $\mathrm{T}_{\mathrm{f}}$ : the temperature corresponding to maximum fluidity; $\mathrm{T}_{\mathrm{r}}$ : resolidification temperature; plastic range $\left(\mathrm{P}_{\mathrm{r}}\right)$ : $\mathrm{T}_{\mathrm{r}}-\mathrm{T}_{\mathrm{s}} ; \log (\mathrm{MF})$ : logarithm of maximum fluidity (ddpm).

Effect of PSD and ST on the Quality of Coke

The effects of PSD and ST addition on the cold strength (M10 and M40) of coke produced from the $5 \mathrm{~kg}$ laboratory-scale coke oven are given in Table 3, M10 of coke is first decreased from 8.76 to 7.90 as the mass concentration of PSD increases from 0 to $3 \%$, followed by the increase from 7.90 to 21.3 as the mass concentration of PSD increases from 3 to $12 \%$. PSD addition can promote M40 of coke when the PSD mass concentration range is $0.3 \%$. The further addition of PSD has a negative influence on M40 because of the decrease of the plasticity of coal/PSD. As for the coal/ST blends, M10 of coke is increased from 8.76 to 24.5 , while M40 is decreased from 77.6 to 52.9 as the mass concentration of ST increases from 0 to $12 \%$. Biomass seems to decrease the coal plasticity because of the two mechanisms: (i) the presence of remaining oxygen-rich compounds that release in the coal plastic stage, which may promote a rapid cross-linking and rapid stabilization of free radicals by 
consuming hydrogen available in the system, and (ii) the addition of biomass particles increases the amount of inert particles (biomass is a physically inert component in the blend with chemical activity) in the plastic stage; thus, the concentration of active components in the plastic stage needed for a good agglomeration is lower [6].

The effects of PSD and ST addition on the hot performances (CRI and CSR) of coke produced from the $5 \mathrm{~kg}$ laboratory-scale coke oven are given in Table 3. Table 3 indicates that CSR of coke increases from 60.6 to 61.6 with the PSD mass concentration increasing from 0 to $3 \%$ and then decreases to 41.9 when the PSD mass percentage is $12 \%$. In contrast, CRI of coke is first decreased, followed by increasing as the PSD mass percentage is above 3\%. As for the ST addition, CSR of coke decreases from 58.4 to 36.3 , while CRI of coke is increased from 31.55 to 42.20 as the mass concentration of ST increases from 0 to $12 \%$. The concentration of $\mathrm{CaO}, \mathrm{K}_{2} \mathrm{O}$, and $\mathrm{MnO}$ in PSD and $\mathrm{ST}$ is relatively high, while the presence of oxides of alkali metals, such as $\mathrm{Ca}, \mathrm{Ba}, \mathrm{Na}$, and $\mathrm{K}$, negatively affects the quality of coke produced with respect to CRI and CSR [9]. On the basis of the experimental results, it can be concluded that the addition of 6\% PSD has no significant influence on the coke quality indexes (both cold and hot performances). Even 3\% PSD addition has a positive effect on the coke qualities. Meanwhile, CRI is decreased by 1.60, and CSR is increased by 1.00. However, when the mass percentage of PSD is above 3\%, M40 and CSR of coke are gradually decreased and M10 and CRI are dramatically increased. As for the ST addition, M40 and CSR of coke are gradually decreased and M10 and CRI are dramatically increased when the ST addition is increased from 0 to $12 \%$. Indeed, the addition of $3 \% \mathrm{ST}$ will reduce the maximum fluidity of blend coals, which leads to the detrimental effect of the coke structure and its final properties. Because of biomass containing more volatile matter, more gases or tar are formed during coal and biomass co-carbonization when the mass concentration of biomass is increased and the specific surface area of coke is also increased. Thus, $\mathrm{CO}_{2}$ can easily diffuse into and react with coke, which results in the decrease of CSR and increase of CRI.

Table 3 Effect of biomass or pitch addition on the coke quality indexes

\begin{tabular}{lllll}
\hline Samples & M10, $\%$ & M40,\% & CRI, \% & CSR, $\%$ \\
\hline RC & 8.76 & 77.60 & 30.56 & 60.60 \\
\hline RC+3\% PSD & 7.90 & 78.20 & 28.96 & 61.60 \\
RC+6\% PSD & 9.30 & 79.50 & 32.07 & 58.10 \\
RC+9\% PSD & 16.90 & 67.80 & 36.10 & 49.90 \\
RC+12\% PSD & 21.30 & 58.40 & 41.70 & 41.90 \\
\hline RC+3\% PSD+1\%PT & 7.70 & 79.90 & 27.94 & 62.20 \\
RC+6\% PSD+1\%PT & 9.20 & 78.90 & 30.65 & 60.40 \\
RC+9\% PSD+1\%PT & 12.30 & 75.30 & 32.17 & 57.30 \\
RC+12\% PSD+1\%PT & 15.20 & 61.30 & 35.25 & 51.40 \\
\hline RC+3\% ST & 13.10 & 78.10 & 31.55 & 58.40 \\
RC+6\% ST & 13.60 & 76.40 & 34.71 & 52.20 \\
RC+9\% ST & 18.30 & 64.50 & 38.36 & 40.50 \\
RC+12\% ST & 24.50 & 52.90 & 42.20 & 36.30 \\
\hline RC+3\% ST+1\%PT & 9.90 & 79.60 & 29.69 & 60.30 \\
RC+6\% ST+1\%PT & 11.50 & 78.80 & 31.32 & 58.50 \\
RC+9\% ST+1\%PT & 12.90 & 76.80 & 34.59 & 49.10 \\
RC+12\% ST+1\%PT & 16.30 & 56.40 & 39.12 & 40.70 \\
\hline
\end{tabular}

Effect of pitch on the Quality of Coke

The effects of $1.0 \%$ pitch addition on the cold strength (M10 and M40) of coke produced from biomass/coal blends co-carbonization are also given in Table 3. Results show that $1.0 \%$ pitch addition could obviously increase the M40 and decrease the M10 when the addition of PSD or ST is varied from $3.0 \sim 12.0 \%$. For example, with the $1.0 \%$ pitch addition, M40 is increased by 7.5 and M10 is decreased by 4.6 when the addition of PSD is $9.0 \%$. As for the ST/coal (9:91) blends, M40 is increased by 12.4 
and M10 is decreased by 5.4. Table 3 compared the hot performances (CRI and CSR) of coke produced from PSD/coal blends or ST/coal blends co-carbonization with and without $1.0 \%$ pitch addition. It can be seen that CSR of coke is obviously increased and CRI is dramatically decreased with $1.0 \%$ pitch addition. With the $1.0 \%$ pitch added, CSR is increased by 7.4 and CRI is decreased by 3.93 when the addition of PSD is $9.0 \%$. As for the ST/coal (9:91) blends, CSR is increased by 8.6 and CRI is decreased by 3.77 . Thus, adding $1.0 \%$ pitch could obviously enhance the coke quality indexes, the maximum amount of PSD and ST addition can be increased to $9.0 \%$ and $6.0 \%$, respectively. The above phenomena can be explained that pitch is a physically active component in the blends, the concentrations of active components and inert components in the plastic stage will be balanced by adding pitch in biomass/coal blends. Thus, adding active components such as pitch in biomass/coal blends can improve the coke quality.

\section{Conclusion}

The thermoplastic properties of the coal are deteriorated by incorporation of the PSD or ST, while it is enhanced by incorporation of the pitch.

The addition of PSD has no significant influence on the coke quality indexes, such as M10, M40, CRI, and CSR, when the mass concentration of PSD is below 6\%, whereas the coke quality indexes are degraded gradually as the mass concentration of PSD is above $6 \%$.

The addition of ST has a negative influence on the coke quality indexes. Even the addition of $3 \%$ ST will reduce the maximum fluidity of blend coals.

Adding $1.0 \%$ pitch could obviously enhance the coke quality indexes, the maximum amount of PSD and ST addition can be increased to $9.0 \%$ and $6.0 \%$, respectively.

\section{Acknowledgements}

The present work is supported by Natural Science Foundation of Hubei Province (16AHB025, 2014CFA030).

\section{References}

1. Y. Wang, G. D. Gao, China's coke consumption analysis and demand forecast. Shandong Metall. 2007, 29 (5): 1- 4.

2. Xie, K.; Li, W.; Zhao, W. Coal chemical industry and its sustainable development in China. Energy 2010, 35 (11): 4349- 4355.

3. J.A. MacPhee, J.F. Gransden, L. Giroux, J.T. Price, Possible $\mathrm{CO}_{2}$ mitigation via addition of charcoal to coking coal blends. Fuel Processing Technology, 2009, 90(1): 16- 20.

4. M.C. Díaz, H. Zhao, S. Kokonya, A. Dufour, and C.E. Snape, The Effect of Biomass on Fluidity Development in Coking Blends Using High-Temperature SAOS Rheometry. Energy \& Fuels, 2012, 26: 1767-1775.

5. M.A. Diéz, R. Alvarez, M. Fernández. Biomass derived products as modifiers of the rheological properties of coking coals. Fuel, 2012, 96 (6): 306- 313

6. L.B. Qin, J. Han, W. Ye, S. Zhang, Q.G. Yan, F. Yu, Characteristics of Coal and Pine Sawdust Co-carbonization. Energy \& Fuel, 2014, 28: 848- 857.

7. S. Kokonya, M.C. Díaz, C. Barriocanal, C.E. Snape, An investigation into the effect of fast heating on fluidity development and coke quality for blends of coal and biomass. Biomass and bioenergy, 2013, 56: 295- 306.

8. A. Guerrero, M.A. Diéz, G.B. Angeles, Influence of charcoal fines on the thermoplastic properties of coking coals and the optical properties of the semicoke. International Journal of Coal Geology, 2015, 147-148: 105- 114.

9. L.J. Li, J.L. Zhang, M. Barati, R. Khann, Z.J. Liu, J.B. Zhong, X.J. Ning, S. Ren, T.G. Yang, V. 
Sahajwalla, Influence of alkaline $(\mathrm{Na}, \mathrm{K})$ vapors on carbon and mineral behavior in blast furnace cokes. Fuel, 2015, 145: 202- 213. 